\title{
Kolb's learning styles of optometry students at the University of the Free State, South Africa
}

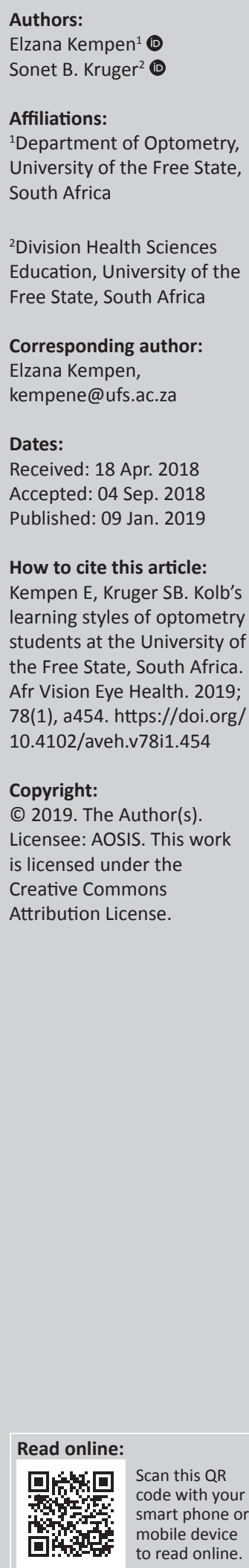

Background: The use of learning styles to guide an educational method is becoming increasingly important, with it contributing to the effectiveness of a learning environment. This study addresses the concept of learning styles with reference to students of the Department of Optometry at the University of the Free State, South Africa - a topic that previously has not received much attention.

Aim: The aim of this study was to identify the learning styles of optometry students as described by Kolb. Kolb's Learning Style Inventory (LSI) was completed by the undergraduate students of the Optometry Department, in order to create a better understanding of how students perceive and process learning and to enhance the learning environment accordingly.

Setting: This study was conducted in the Optometry Department at the University of the Free State.

Methods: Undergraduate optometry students $(N=106)$ who were registered for the 2014 academic year and agreed to participate in the study completed Kolb's LSI to determine their learning styles. Descriptive statistics for categorical data and medians and percentiles for numerical data were calculated.

Results: A response rate of $94.6 \%$ was achieved, with female students representing the majority $(72.6 \%)$. The converger learning style was identified as the most preferred learning style among most students, followed by the assimilator, accommodator and diverger learning styles.

Conclusion: Knowledge of Kolb's learning styles created a better understanding of how students learn, which will benefit the facilitator as well as the students. It is recommended that to enhance the learning environment, curriculum delivery and education methods, the learning styles of students should be kept in mind.

\section{Introduction}

Prajapati et al. ${ }^{1}$ declare that improving teaching and learning for students is a key issue in higher education. Teaching and learning activities are constructed within a theoretical framework that guides the planning, development and implementation of an education strategy. Current educational strategies need to be revitalised to minimise the wasting of talent, to prevent the failure of academic careers, to improve graduate production and to promote economic, social and cultural development. It is important that any education strategy consider current realities, as there is evidence that mismatches between the realities and the assumptions underlying the traditional structure of teaching and learning approaches are common. ${ }^{2}$

The concept of learning styles emerged when higher education institutions started using integrated, interactive and active teaching strategies, rather than traditional methods. During this time, it became evident that learning psychology and study methods of individuals should be taken into account to enhance the learning environment for students. ${ }^{3}$ Gurpinar et al. ${ }^{4}$ assert that identifying the learning styles of students enables the adoption of a more student-centred teaching approach and the development of lifelong learners who possess the skill of self-learning. The skill of recognising and reacting to different styles of learning will maximise learning for students, regardless of the environment. Furthermore, it is considered a vital skill that the autonomous learner in any career path should possess. ${ }^{5}$ In an attempt to promote lifelong learning, the emphasis is on learning to learn, which is a ramification of the learner-centred approach of knowledge that is seen as something that needs to be constructed by an active learner and not just absorbed by a passive learner. ${ }^{4}$ 
Learning styles can develop and change over time ${ }^{6}$ and should be incorporated within an education strategy that permits a learner to choose and use the appropriate style of learning. ${ }^{7}$ Eubank and Pitts ${ }^{8}$ compare the learning styles of Generation Y (born 1981-2000) optometry students with those of Generation X (born 1960-1980) optometry students at the Southern College of Optometry in Memphis. The dominant learning style was identical for the two generations, though a demonstrable shift was found in the way they perceive information. Generation Y students preferred to rely more on concrete experience, own imagination and intuition, in other words added feeling to learning. Generation $X$ students, on the other hand, made use of abstract conceptualisations, where information is perceived through thinking. This difference can be seen as neither good nor bad, but highlights the need for educators to attend to the needs of students and to understand the variations in learners' styles and approaches to enhance the learning experiences of the current generation of optometry students. ${ }^{9}$ Pheiffer et al. ${ }^{6}$ conclude that using learning styles could assist in the creation of learner identities, by making students more aware of where they fit in, as learners, in different contexts.

Kolb's Learning Style Inventory (LSI) was chosen as the vehicle to determine the learning styles of optometry students at the University of the Free State (UFS) in Bloemfontein, South Africa. Kolb's LSI has been identified as the most influential learning style model, ${ }^{10}$ and it is frequently administered for students in health sciences. ${ }^{4}$ It differs from other learning style and personality tests, as it is based on the development of how humans learn, with the view that learning based on experience is a fundamental part of development. ${ }^{8}$

Manolis et al. ${ }^{11}$ acknowledge that the work of Kolb, although influential, had not escaped criticism, as the instrument assumes that an individual may use only one learning style. These authors argue that the theory on which the model is based relates more to a map of the learning process than a learning style. However, Kolb's model helps to understand the learning preferences of students. With any learning style measurement there will be criticism; therefore, Prajapati et al. ${ }^{1}$ claim that a perfect learning style measure is a fantasy.

In the experiential learning theory (ELT), Kolb defines learning as a process whereby knowledge is created through the transformation of experience. Kolb identifies two modes of learning, namely perception and processing. The classification of learning styles further includes perception of knowledge that may take place through abstract conceptualisation or through concrete experience, as mentioned earlier with the generation differences. The processing of information can be donethrough reflective observation or active experimentation. ${ }^{12}$

Kolb's learning cycle proposes four valuable and distinctive components that can be utilised to enhance the learning experience. The cycle of experiential learning starts with the completion of a concrete experience. This step involves a direct learning experience and adds feelings and emotion to the learning process. This step is followed by reflective observation. Students have to make sense of the experience within this stage of the cycle. It entails students thinking about the experience from many perspectives via personal biases and collecting details and new information on that experience. From these newly created insights, a theory or abstract conceptualisation may be constructed. These should then be tested through active experimentation that involves the manipulation of the external world to modify the new experience to follow. ${ }^{12}$ According to Kolb, learning takes place when one or more of the four modes of the ELT are utilised to resolve a learning problem; when an individual develops a preference for two of the four modes, it is described as a learning style. Figure $1^{11}$ provides a diagrammatic representation of Kolb's learning cycle and learning styles and how they interact with one another.

Individuals who prefer the diverger learning style learn through creating and generating new ideas and imagining new possibilities. ${ }^{10}$ Assimilators tend to focus less on people and more on ideas and abstract concepts that are logical and reliable, but not necessarily practical. ${ }^{12}$ In contrast, individuals described as convergers prefer interaction with technical tasks or problems, rather than social and interpersonal issues. Convergers further tend to solve problems practically and are decision makers. ${ }^{10}$ Accommodators will be found in leadership roles, where they take action, have the opportunity to show initiative and are willing to take risks when it comes to gathering information, which they acquire from others, rather than through personal examination. ${ }^{12}$

The Department of Optometry at the UFS makes use of various educational methods to enhance the learning experience in didactic and clinical education, in order to provide students with the skills set out by the Professional Board of Optometry and Dispensing Opticians. ${ }^{13}$ The students should achieve the necessary knowledge, skills, professional

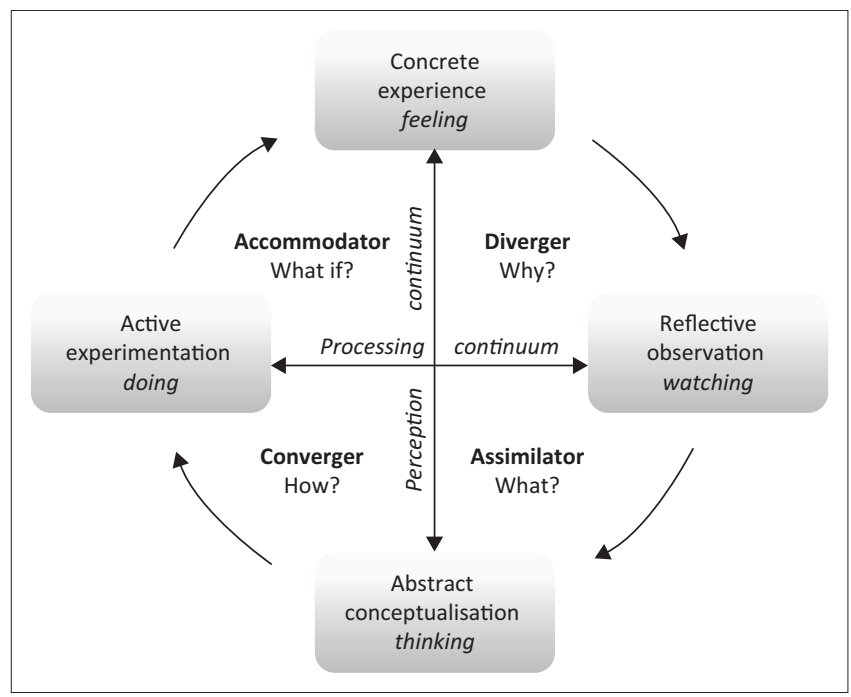

Source: Adapted from Manolis C, Burns DJ, Assudani R, Chinta R. Assessing experientia learning styles: A methodological reconstruction and validation of the Kolb learning style inventory. Learn Individ Differ. 2013;23:44-53. https://doi.org/10.1016/j.lindif.2012.10.009 FIGURE 1: Kolb's experiential learning model and learning styles. 
thinking, behaviour and attitudes in all ramifications of primary eye and healthcare to be able to pursue their profession as optometrist.

The problem that was identified is the lack of knowledge of the learning styles of the optometry students at the UFS. By identifying their learning styles, educational methods may be tailored and students' self-awareness of their role in their own learning may be enhanced.

The findings of this study suggest that Kolb's learning cycle may play an important role in teaching and learning at the Department of Optometry at the UFS. The aim of this study was to identify and describe the learning styles of the abovementioned student body by using Kolb's LSI. Mumford, as reviewed by De Vita, ${ }^{14}$ states that learning style variations cannot be assumed. These different learning styles must be identified to enable the outlining of an appropriate class profile to customise the matching of the learning style of students and the facilitator of learning.

\section{Methods}

Students enrolled in the undergraduate optometry programme at the UFS in $2014(N=112)$ were invited to voluntarily participate in this study. No sampling method was used, as the total population was included in the study. This population included students of both genders in both the Afrikaans and English classes (at the time, the UFS had a parallel-medium language policy).

Students were introduced to the concept of learning styles and information was provided on the importance of identifying your learning style. The data were then collected during scheduled contact sessions on the campus of the UFS. Completion of the LSI was voluntary. In total, 106 students anonymously completed Kolb's LSI 10-item self-assessment instrument. The LSI required participants to identify the learning statement that represented their learning style best by rank-ordering words that describe the characteristics of learning styles. The measurement is ipsative, which means that respondents compare two or more desirable options and select the one that is most preferred; scores on one dimension are dependent on the measurement relative to the other scores on that response set.

Descriptive statistics were used to describe the four learning styles associated with Kolb's ELT, namely converger, assimilator, accommodator and diverger. These learning styles were compared with the categorical variables (gender, year group and ethnicity). Fisher's exact test (or chi-square statistic) was used to investigate the effects of the categorical variables on the different learning styles.

The data were analysed and, based on the results, the researchers described the most preferred learning styles, as described by Kolb, of the undergraduate students of the Optometry Department at the UFS.

\section{Ethical considerations}

Approval to conduct the research was obtained from the Health Sciences Research Ethics Committee of the Faculty of Health Sciences at the University of the Free State.

\section{Results \\ Demographic data}

With 106 students voluntary completing the questionnaire, a response rate of $94.6 \%$ was achieved. Upon reviewing the demographic data, it was found that the respondents were distributed in approximately equal numbers across the four academic years of study (Figure 2).

The sample population was dominated by female students, with only $27.4 \%$ being male students. The students' ages ranged between 18 and 31 years, with a median age of 20 years. White students made up $74.5 \%$ of the sample population, followed by $14.2 \%$ Indian and $11.3 \%$ black students.

\section{Learning styles}

A total of 123 learning styles were identified among the 106 participating students. More learning styles than the number of students were found, because 14 students (13.2\%) indicated that they preferred a combination of two learning styles. For one student $(0.9 \%)$ no dominant learning style could be identified, as equal measurements were found in all four quadrants of the LSI.

Figure 3 presents the learning styles of the participating students. Of the 123 learning styles identified, 44 students $(41.5 \%)$ made use of the converger learning style, thus making it the preferred learning style in this population.

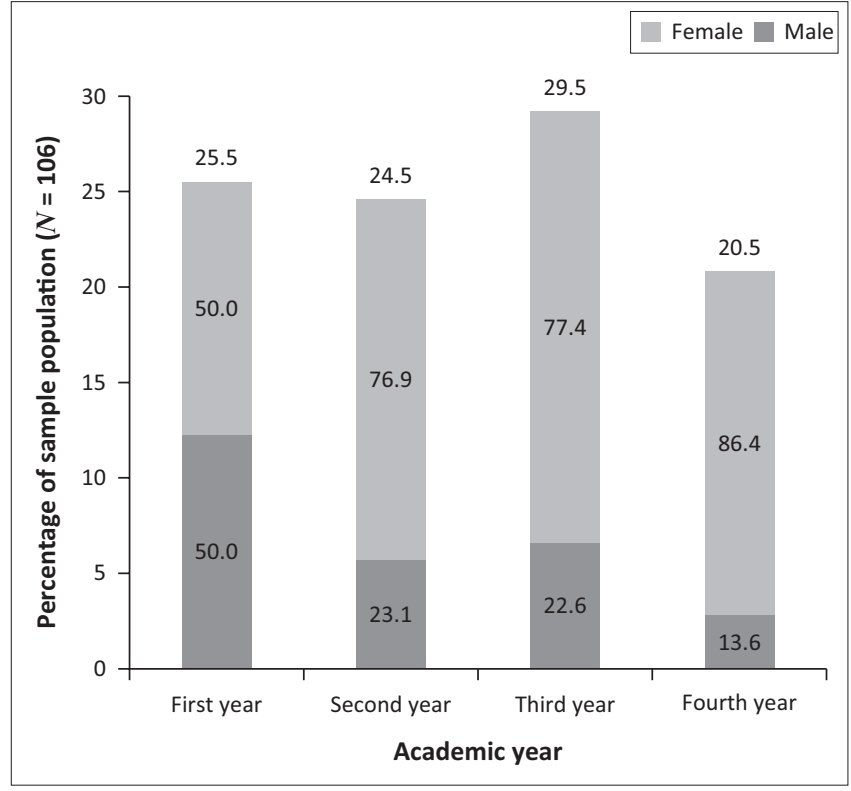

FIGURE 2: Distribution of undergraduate optometry students who participated in the study $(N=106)$ with regard to gender and number of students per academic year. 
The two dominant learning styles of the first-, second- and fourth-year students were the converger and assimilator learning styles. The third-year academic group also identified the converger learning style as the most preferred learning style, but their second preferred learning style was different from the other years as they identified the accommodator learning style as their second preferred learning style.

\section{Categorical variables}

In order to investigate the effect of age, gender, academic year and ethnicity on learning styles, the learning styles were compared in categorical variables of age, gender, academic year and ethnicity. In this sample population, none of these variables had any effect on the learning styles; $p$-values of $>0.05$ were found, which indicates that no statistically significant differences were found for the variables tested.

\section{Discussion}

In recent years, literature about learning styles has increased significantly. ${ }^{5}$ However, little research has been conducted regarding the learning styles of undergraduate optometry students. ${ }^{1}$ For this reason, this study was conducted to evaluate the learning styles of optometry students at the UFS in South Africa and to compare the findings with those of studies in other health sciences programmes globally.

In contrast to reports in literature,,$^{3,5,7,8,12}$ no statistical differences were found for comparisons of learning styles of optometry students to categorical variables, such as gender, age, academic year group and ethnicity. It may be argued that categorical variables do not have an impact on learning styles, as the sample population was fairly

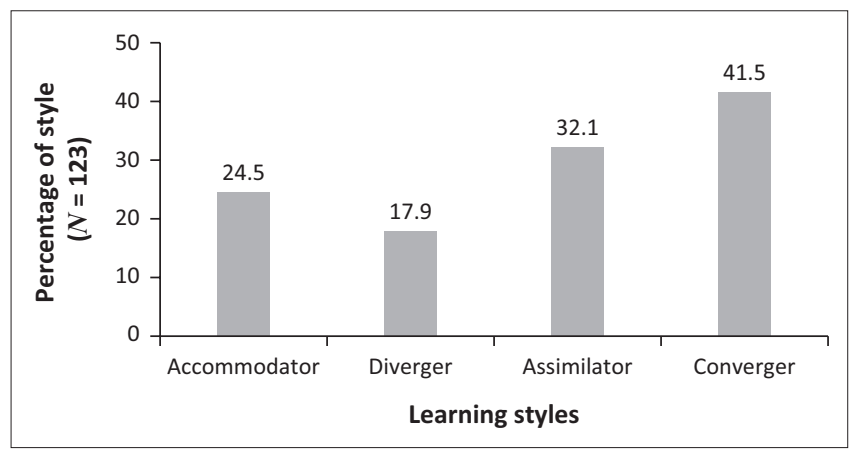

Note: The distribution of the four learning styles per academic year group is shown in Table 1.

FIGURE 3: Distribution of learning styles $(N=123)$ among undergraduate optometry students at the University of the Free State in $2014(N=106)$. homogenous, with the majority of respondents being female students. Mainemelis et al. ${ }^{7}$ found some noteworthy differences in terms of gender. They concluded that female students had a tendency to learn more when they could reflect on an observation made or an experience, while male students preferred abstract conceptualisation. This finding reduces the complexity of the implementation of learning methods as a pedagogy in the Department of Optometry, as the focus can be on groups, instead of on individuals.

The preferred learning style of optometry students at the UFS was the converger learning style $(41.5 \%)$. Students who prefer the converger learning style tend to choose medical science as their field of study, as this is an environment requiring students to think on their feet, to make immediate decisions and to solve problems practically. ${ }^{4}$ The assimilator learning style was identified by $32.1 \%$ as their dominant learning style, which correlates with previous findings that the assimilator style was observed more frequently in optometry education programmes. ${ }^{8}$

In a study by Vawda ${ }^{15}$ on the learning styles on first-year students at the Faculty of Health Sciences, Nelson Mandela Metropolitan University, it was found that their most represented learning style was the diverger followed by the accommodator and assimilator. In contrast to our findings, the least represented style was the converger. The sample population in Vawda's study consisted mainly of nursing students, which could have contributed to the difference in the preferred learning style from the current study. Similar to our findings, Gurpinar et al. ${ }^{4}$ found that the majority of their medical students at Akdeniz University in Turkey preferred the assimilating and converging learning style and concluded that most students had chosen a faculty in accordance with their learning style. In accordance, junior occupational therapist students in Australia were also identified to have the converger learning style as their preferred learning styles. ${ }^{16}$ Students at the Faculty of Allied Health Sciences, Kuwait University were again predominantly assimilators. ${ }^{16}$

The converger and assimilator learning styles, which were identified in the current study by the greatest number of students as their preferred learning styles, involve the same way of perceiving knowledge, but different ways of processing information. ${ }^{12}$ Figure 4 illustrates the difference.

TABLE 1: Distribution of learning styles per academic year group of optometry students at the University of the Free State in 2014 ( $N=106)$.

\begin{tabular}{|c|c|c|c|c|c|c|c|c|}
\hline \multirow[t]{3}{*}{ Learning style } & \multicolumn{8}{|c|}{ Academic year group } \\
\hline & \multicolumn{2}{|c|}{1 st year $(N=27)$} & \multicolumn{2}{|c|}{2 nd year $(N=26)$} & \multicolumn{2}{|c|}{ 3rd year $(N=31)$} & \multicolumn{2}{|c|}{4 th year $(N=22)$} \\
\hline & $N$ & $\%$ & $N$ & $\%$ & $N$ & $\%$ & $N$ & $\%$ \\
\hline Accommodator & 9 & 33.3 & 3 & 11.5 & 10 & 32.3 & 4 & 18.2 \\
\hline Diverger & 4 & 14.8 & 7 & 26.9 & 5 & 16.1 & 3 & 13.6 \\
\hline Assimilator & 11 & 40.7 & 8 & 30.8 & 8 & 25.8 & 7 & 31.8 \\
\hline Converger & 12 & 44.4 & 11 & 42.3 & 13 & 41.9 & 8 & 36.4 \\
\hline Total number of learning styles & 36 & - & 29 & - & 36 & - & 22 & - \\
\hline
\end{tabular}

$N$, number. 


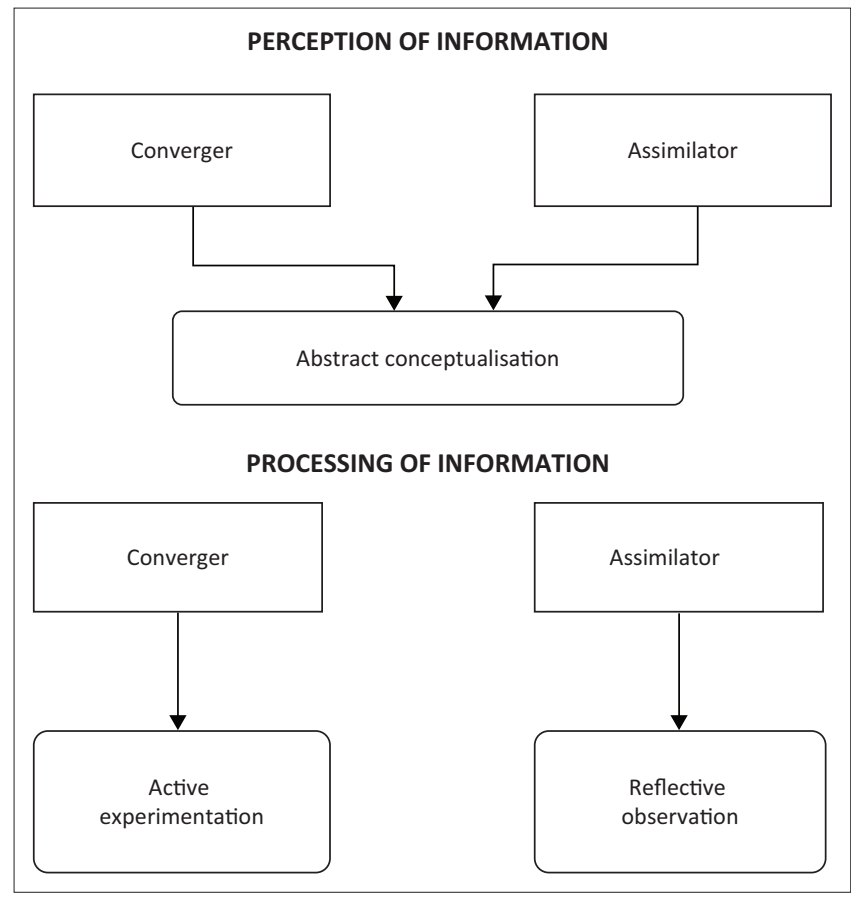

FIGURE 4: The perception and processing of information of the converger and assimilator learning styles.

To explain further, students at the Department of Optometry at the UFS prefer to perceive information through the application of logic and thought. The majority of the students chose to process the information perceived by being involved in practical exercises, while a large group chose to observe a practical demonstration and reflect on the demonstration.

\section{Implications for practice}

It can be argued that, in order to produce confident and independent optometrists, students should be provided with opportunities to combine and integrate skills and knowledge in the context of experience. It is therefore important for the facilitator to know how to enhance the learning experience for the student with the knowledge of the preferred learning style. Equally important, with the student knowing his or her preferred learning style, they can adapt to optimise their own learning.

Emphasis should be placed on improving the teaching methods aimed at supporting the learning that takes place according to the two dominant learning styles that had been identified, namely the converger and the assimilator learning styles. The way a learning style is used to guide a teaching method varies according to the learning objectives and needs of the students. Depending on the learning objective, the facilitator may choose to match or mismatch the instruction to the dominant learning styles identified, or to follow a multi-style approach to address all the learning dimensions. According to Romanelli et al., ${ }^{5}$ the mismatch theory could be applied to support students to develop their academic capabilities and to learn more integrated habits. Doing so will provide an opportunity for the facilitator to expand the spectrum of activities with which they are comfortable, and hence, this will ensue the development of more integrated learners.

Research has found that multi-style teaching that utilises all four learning modes is still the best practice..$^{5}$ Therefore, although the concrete experience learning mode was identified as the least-preferred learning mode among students of the Department of Optometry at the UFS, it should not be disregarded as a learning mode. This mode of learning is an important aspect of health professions education, especially in the current optometry curriculum at the UFS. Students see patients on a daily basis in their third and final year, therefore making it a direct reflection of the profession that students aspire to enter.

Keeping the preferred learning styles identified in mind, lectures and practical sessions should provide opportunities to enable better meaning of experiences and construction of knowledge that is theoretical and comprehensive. Therefore, lectures and practical sessions should offer learning opportunities that involve logical thinking and ideas that will result in an understanding of the problem and provide opportunities to actively plan for the next experience. Lectures should include simulation, role-play, case studies and brainstorming activities, to accommodate the different aspects of Kolb's learning cycle. In addition, assessments should be planned to complement teaching and learning.

\section{Conclusion}

The definition of a learning style involves aspects such as how a student perceives, interacts and responds to a learning environment. ${ }^{17}$ A learning style determines how a student will run the metaphorical curriculum race to overcome obstacles and hurdles ${ }^{18}$ and achieve the outcomes that have been set, to become a competent optometrist.

From the literature ${ }^{1,6,8,9}$, it is clear that knowledge of learning styles and ways to adjust teaching strategies accordingly will not only develop students into self-regulated and autonomous learners but also increase graduation rates of universities and address the diversity of students. After an analysis was made, it was found that the current curriculum at the Optometry Department of the UFS involves all aspects of the experiential model described by Kolb. Therefore, in identifying learning styles, educators in the Optometry Department will know how students prefer to perceive and process knowledge, and education strategies can be aligned to involve the specific learning styles of the students in the learning process.

\section{Acknowledgements}

The authors would like to thank Ms Hettie Human for her language editing support.

\section{Competing interests}

The authors have no conflicts of interest with regard to the writing of this article. 


\section{Authors' contributions}

This study was conducted as a mini-dissertation towards E.K. obtaining an M.HPE at the University of the Free State. S.B.K. provided leadership on the master's mini-dissertation. E.K. compiled the final article.

\section{Funding information}

Health and Welfare Sector Education and Training Authority (HWSETA) provided a bursary to fund this study.

\section{References}

1. Prajapati B, Dunne $M$, Bartlett $H$, Cubbidge $R$. The influence of learning styles, enrolment status and gender of academic performance of optometry undergraduates. Ophthalmic Physiol Opt. 2011;31(1):69-78. https://doi. org/10.1111/j.1475-1313.2010.00798.x

2. Council on Higher Education (CHE). A proposal for undergraduate curriculum reform in South Africa: The case for a flexible curriculum structure [document on the Internet]. Pretoria: CHE; 2013 [cited 2016 Feb 03]. Available from: http:// www.che.ac.za/sites/default/files/publications/Full Report.pdf

3. Davis MH. AMEE medical education guide no. 15: Problem-based learning A practical guide. Med Teach. 1999;21(2):130-140. [PMID 21275726]. https://doi. org/10.1080/01421599979743

4. Gurpinar E, Bati $\mathrm{H}$, Tetik C. Learning styles of medical students change in relation to time. Adv Physiol Educ. 2011;35(3):307-311. https://doi.org/10.1152/ advan.00047.2011

5. Romanelli F, Bird E, Ryan M. Learning styles: A review of theory, application, and best practices. Am J Pharm Educ. 2009;73(1):1-5. https://doi.org/10.5688/ aj730109
6. Pheiffer $\mathrm{G}$, Andrew $\mathrm{D}$, Green $\mathrm{M}$, Holley $\mathrm{D}$. The role of learning styles in integrating and empowering learners. Invest Univ Teach Learn. 2003;1(2):36-39.

7. Mainemelis $C$, Boyatzis R, Kolb D. Learning styles and adaptive flexibility. Testing experiential learning theory. Manag Learn. 1999;33(1):1-33.

8. Eubank TF, Pitts J. A comparison of learning styles across the decades. Optom Educ. 2011;36(2):72-75.

9. Vaughn L, Baker R. Teaching in the medical setting: Balancing teaching styles, learning styles and teaching methods. Med Teach. 2001;23(6):610-612. https:// doi.org/10.1080/01421590120091000

10. Kayes DC. Internal validity and reliability of Kolb's learning style inventory version 3 (1999). J Bus Psychol. 2005;20(2):249-257. https://doi.org/10.1007/ s10869-005-8262-4

11. Manolis C, Burns DJ, Assudani R, Chinta R. Assessing experiential learning styles: A methodological reconstruction and validation of the Kolb learning style inventory. Learn Individ Differ. 2013;23:44-53. https://doi.org/10.1016/ j.lindif.2012.10.009

12. Kolb AY, Kolb DA. The Kolb learning style inventory - Version 3.1. 2005 Technical specifications [document on the Internet]. 2005 [cited 2016 Feb 03]. Available from: http://www.whitewater-rescue.com/support/pagepics/Isitechmanual.pdf

13. CHE and HPCSA. Memorandum of understanding between the Council on Higher Education and the Health Professions Council of South Africa. Pretoria: CHEHPCSA; 2013.

14. De Vita G. Learning styles, culture and inclusive instruction in the multicultural classroom: A business and management perspective. Innovat Educ Teach Int. 2001;38(2):165-174. https://doi.org/10.1080/14703290110035437

15. Vawda A. The learning styles of first year university students [unpublished thesis] Port Elizabeth: Nelson Mandela Metropolitan University; 2005.

16. Manee F, Nadar M, Jahrami H. Learning styles of allied health sciences students at Kuwait University. Int J Ther Rehabil. 2013;20(5):255-259. https://doi. org/10.12968/ijtr.2013.20.5.255

17. Kazu IY. The effect of learning styles on education and the teaching process. J Soc Sci. 2009;5(2):85-94. https://doi.org/10.12968/ijtr.2013.20.5.255

18. Marsh CJ. Key concepts for understanding curriculum. 4th ed. New York: Routledge; 2009. 